\section{Psychiatry and psychology}

\section{G180 EVIDENCE OF LIMBIC SYSTEM IMBALANCE IN EARLY-ONSET ANOREXIA NERVOSA}

B. Lask, I. Gordon, U. Chowdhury, D. Christie, B. Watkins, H. Watt, A. Van Schagen. St. George's Eating Disorders Service, London; Great Ormond Street Hospital for Children, London; Huntercombe Manor Hospital, Berkshire; and Middlesex Hospital London

Aims: Functional neuroimaging studies in adults with anorexia nervosa suggest temporal lobe abnormalities. The only functional neuroimaging study of children and adolescents with anorexia nervosa, using Single Photon Emission Computerised Tomography (SPECT) to assess regional cerebral blood flow ( $\mathrm{rCBF}$ ), found hypoperfusion in the temporal lobes of 13 out of 15 patients'. This study attempts to replicate and explain such findings.

Methods: Children and adolescents with anorexia nervosa underwent $\mathrm{rCBF}$ examination using SPECT.

Results: 30 children (27 girls and 3 boys) with anorexia nervosa, mean age 14.5 years, mean wt/ht ratio $84.22 \%$, were scanned. Significant hypoperfusion was noted in at least one area of the brain in 21 of the 30 patients $(70 \%)$. Eleven had multiple areas of asymmetry and ten a single focus. The hypoperfused areas were the temporal lobe (left $n=9$, right $n=6$ ), thalamus (left=5, right=2), basal ganglia $($ left=1, right=2), parietal lobe $(l \mathrm{eft}=5, \mathrm{right}=1)$, frontal lobe $(\mathrm{left}=2)$ and pre-frontal area (left=2, right=1).

Conclusion: Our findings provide additional evidence of regional cerebral hypoperfusion in children and adolescents with anorexia nervosa. The varying sites of reduced blood flow suggest limbic system dysfunction rather than a specific focal abnormality. The implications of these findings and how they relate to neuropsychological abnormalities and eating disorder psychopathology will be explored.

1. Gordon I, Lask B, Bryant-Waugh R, et al. (1997). Childhood-onset anorexia nervosa: towards identifying a biological substrate. Int J Eat Disord 1997;22:159-65.

\section{G181 COPING STRATEGIES IN CHILDREN WITH INFLAMMATORY BOWEL DISEASE}

C. Noake, A.G. Thomas. Booth Hall Childrens Hospital, Manchester, UK

Background: In a meta-analytic review inflammatory bowel disease (IBD) was shown to have a greater effect on mental health than other chronic diseases in children.

Aims: To determine whether: 1) children with IBD use different coping strategies compared to controls, 2) whether children with IBD use different coping strategies for illness and non-illness related situations and 3) whether quality of life (QoL) in the children with IBD is related to the coping strategies employed.

Methods: Children with IBD attending the outpatient clinic were asked to complete IMPACT (an instrument to measure QoL in childhood IBD) and KIDCOPE (an instrument to assess coping strategies in children). Control children just completed KIDCOPE.

Results: 15 children with IBD (mean age $14.75 \mathrm{yr}$ ) and 13 controls (mean age $15.42 \mathrm{yr}$ ) completed the questionnaires. Of the 10 coping strategies assessed by KIDCOPE the only significant difference between patients and controls was in the efficacy of the coping strategy of "trying to calm myself by talking to myself, praying, taking a walk, or just trying to relax" $(p<0.05)$. Children with IBD found it more useful to "turn to family, friends or other adults" for situations relating to their illness than in non-illness related situations $(p<0.03)$. There were significant correlations between the "negative" coping strategies of social withdrawal $(R=0.67)$, self blame $(R=0.71)$ and worse QoL. Children with better QoL were more likely to use acceptance as a coping strategy $(R=0.54)$.

Discussion \& Conclusion: Children with IBD generally use the same coping strategies as controls and in illness and non-illness related situations. The correlation between certain coping strategies and better or worse QoL does not explain cause \& effect but does raise the possibility that teaching children positive coping strategies may help to improve their QoL.

\section{G182 GASTROSTOMY-TUBE FEEDING IMPROVES QUALITY OF LIFE IN CAREGIVERS OF DISABLED CHILDREN}

P.B. Sullivan', A.G. Thomas ${ }^{2}$, M. Eltumi ${ }^{3}$, H. Grant' ${ }^{\prime}$ B. Lambert' E. Mclean $^{3}$, A. Bachlet', E. Juszczak', C. Jenkinson'. 'University of Oxford,
Department of Paediatrics, Oxford; 'Booth Hall Children's Hospital, Manchester; ${ }^{3}$ Watford General Hospital, Watford; ${ }^{4}$ Centre for Statistics in Medicine, Institute of Health Sciences, University of Oxford

On the basis of clinical experience, gastrostomy-tube (G-tube) feeding is increasingly used for severely disabled children but many parents are apprehensive about implementing G-tube feeding. There have been no prospective studies evaluating this intervention, therefore little evidence exists from which to advise caregivers. The aim of this study was to evaluate Quality of Life (QoL) in caregivers before and after G-tube insertion.

Methods: The QoL assessment tool was a standardized and validated SF-36 version II together with a specifically developed 26 item questionnaire with items relating to the condition of the child in general, practicalities of care, feeding and stresses for the caregiver. The QoL questionnaire was given to primary caregivers of 50 children with severe neurological impairment before and 6 and 12 months after G-tube insertion. Structured interviews were also conducted before and at 6 and 12 months post intervention. Scores for each domain of the SF-36 were calculated for caregivers before and at 6 and 12 months post G-tube insertion and compared with accepted normal values (Oxford Healthy Life Survey).

Results: The caregivers routinely scored lower (Table) than the normal reference range (OHLS), but average scores for each domain increased after G-tube placement. For the CP-specific questionnaire the cumulative average score increased by $4.2 \%$ at six months and by $5.7 \%$ points at 12 months post $\mathrm{G}$-tube.

Conclusion: This study has demonstrated that the use of G-tube feeding in children with cerebral palsy is associated with an improved QoL for caregivers.

\begin{tabular}{|c|c|c|c|c|}
\hline \multicolumn{5}{|l|}{ Abstract G182 } \\
\hline \multirow[b]{2}{*}{ Domain } & \multicolumn{4}{|c|}{$\begin{array}{l}\text { SF-36 Scores of Caregivers Pre and Post } \\
\text { G-Tube (G) }\end{array}$} \\
\hline & $\begin{array}{l}\text { Pre G } \\
\text { (N) }\end{array}$ & $\begin{array}{l}6 m \text { post } G \\
(N)\end{array}$ & $\begin{array}{l}12 \mathrm{~m} \text { post } \\
(\mathrm{N})\end{array}$ & OHLS \\
\hline Physical problems & $73.3(43)$ & $74.0(30)$ & $81.5(25)$ & 85.8 \\
\hline Emotional problems & $68.2(43)$ & $73.6(29)$ & $80.2(27)$ & 82.9 \\
\hline Social functioning & $65.9(44)$ & $63.8(30)$ & 76.9 (27) & 88 \\
\hline Mental health & $62.8(45)$ & $67.0(32)$ & $70.4(27)$ & 73.8 \\
\hline Energy/vitality & 45.7 (45) & 49.2 (32) & 57.6 (27) & 61.1 \\
\hline Health perception & 65.1 (44) & $65.4(31)$ & 76.0 (27) & 73.5 \\
\hline
\end{tabular}

\section{G183 PRAGMATIC COMMUNICATION SKILL DEFICITS IN CONDUCT DISORDER: A CLINICAL AND COMMUNITY SURVEY}

J. Gilmour', B. Hill', M. Place', D.H. Skuse'. 'Behavioural and Brain Sciences Unit, Institute of Child Health, 30 Guilford Street, London WCIN IEH; ${ }^{2}$ Child and Family Unit, Sunderland Royal Hospital, Kayll Road, Sunderland SR4 7TP

Increasing numbers of children are being excluded from mainstream education because of disruptive behaviour. Those at highest risk are male, they have special educational needs, and they live in areas of social deprivation. Their behavioural problems are thought to have their origins in inappropriate socialization experiences. In this study we tested the hypothesis that a substantial minority of children excluded from elementary school have a primary deficit in pragmatic communication skills of an autistic character. Pragmatics may be defined as the appropriate use and interpretation of language in relation to the context in which it occurs. Using the Children's Communication Checklist, we surveyed 113 children with autism, an autistic spectrum disorder or conduct disorder who had been referred for clinical investigation. Also, 44 children who had been excluded from school in an inner-London borough and 60 normal comparisons. The age range of the sample was 4 to 17 years, mean $10 \mathrm{yr}$. ( $77 \%$ male). We found $50 \%$ of the clinically referred children with conduct disorders had deficits in their pragmatic skills that were at least as severe as those of autistic children, independent of IQ. One quarter of the excluded children had an equivalent deficit. These findings have both theoretical and practical implications. First, they provide further support for the idea that autistic patterns of communication coexist with other psychiatric conditions, especially in boys. Second, they imply that neurodevelopmental disorders may be at least as important 
as socialization experiences in causing disruptive behaviour in this age group. Thirdly, they indicate that the management of disruptive children could profitably be addressed to ameliorating their associated communication skill problems.

\section{G184 PREVALENCE OF MENTAL HEALTH PROBLEMS IN EAST LONDON: A REPORT FROM THE RELACHS STUDY}

M. Haines, S. Stansfeld, R.M. Viner, S.C. Taylor, J. Head, K. Bhui, S. Hillier, R. Booy. Queen Mary, University of London, \& University College London

Aims: National and international surveys have provided little data on the health of ethnic minority and socially deprived adolescents. The aim of the RELACHS study was to conduct an adolescent health survey in one of the most deprived and ethnically varied areas in the UK. This report describes the prevalence of psychological problems in the RELACHS cohort compared with national levels.

Methods: RELACHS is a cross-sectional school-based epidemiological study of a representative sample of 2790 adolescents from Year 7 or Year 9 attending 28 schools in East London in 2001. Pupils completed questionnaires in English individually in classrooms. Mental and physical health, health behaviours, social capital, and socio-demographic factors were assessed using appropriate and valid measures. Mental health was assessed using the Strengths and Difficulties Questionnaire (SDQ).

Results: 2790 children participated (response rate 84\%). 49\% were male. $74 \%$ of the sample was non-white. Mean SDQ total scores on RELACHS for 11-14 year old adolescents (Boys 12.2, se 0.13; Girls 12.7, se 0.14) were higher than mean SDQ scores in the national 'Mental Health of Children and Adolescents in Great Britain' study for 11-15 year olds (Boys 10.5, SD 5.1; Girls 10.0, SD 5.3) (Meltzer et al, 2000). The proportion of high scorers (SDQ total score $>18$ ) on the SDQ in RELACHS was $13.9 \%$ for boys and $17.1 \%$ for girls compared with $9.4 \%$ for boys and $9 \%$ for girls nationally.

Conclusions: Rates of psychological distress in adolescents in East London are higher than national rates. This is in keeping with earlier studies showing an excess of psychiatric morbidity in young people in deprived urban areas. Part of the explanation could relate to high rates of social deprivation and part to cultural influences. These baseline results will form the foundation for a longitudinal prospective study of adolescent health.

\section{G185 DOES BRIEF THERAPY FOR BEHAVIOURAL PROBLEMS IN UNDER 5S GIVEN IN A PAEDIATRIC HOSPITAL CLINIC SETTING HAVE LASTING BENEFIT UP TO 2 YEARS POST INTERVENTION?}

M. Blair, M. Fielder, R. Glynn. Northwick Park Hospital, NWLH Trust, Harrow, Middlesex, UK

Aim: To establish the views of parents on the long term effects of brief behavioural therapy and parental guidance given in the context of a hospital based specialist clinic.

Methods: Semi structured telephone parental questionnaire. Intervention: 'brief' behaviour therapy and parental guidance given by consultant paediatrician or staff grade doctor. Problems were classified by DSM4 -PC.

Results: Of 85 referrals in year, $71(69 \%)$ attended, 59 fulfilled the inclusion criteria. 37/59 (63\%) participated. Modal age; 3years, 1.5:1 male to female ratio. Problems sleep $15(41 \%)$, tantrums/opp defiance; $10(27 \%)$, hyperactivity; $5(14 \%)$, wetting and soiling;4 (11\%) feeding disorder $3(8 \%)$. 25/37 (68\%) perceived that there had been improvement directly attributable to the intervention. $12 / 37(32 \%)$ felt there had been no improvement at all. Relapse rate was $11 \%$ Two years post intervention, $20(54 \%)$ still had no problems, $15(40 \%)$ had continued and 2 had intermittent problems. The clinic was viewed positively by the majority of parents especially as a source of advice and reassurance.

Conclusion: Hospital based 'brief' behavioural therapy by paediatricians for the under fives is perceived by parents as an effective short term therapy with long term benefits in about half those referred. This has implications for case selection and coworking.

\section{G186 A PROSPECTIVE STUDY OF ADMISSIONS TO ACUTE PAEDIATRIC WARDS OF CHILDREN REQUIRING CHILD AND ADOLESCENT MENTAL HEALTH SERVICES}

A.C. Peet, P. Carter. Birmingham Children's Hospital and Walsall Manor Hospital, UK
Aims: To determine the impact on acute paediatric services of children requiring Child and Adolescent Mental Health Service (CAMHS) input; and the needs and characteristics of the population involved

Methods: A prospective study of acute admissions to paediatric services of patients (including deliberate self-harm) requiring CAMHS was carried out. Six hospitals took part and data collected for over 3 months.

Results: Data were collected from 136 admissions. $82 \%$ involved white children, $76 \%$ were girls and $9 \%$ had learning difficulties. The incidence was approximately 11 per 10000 child population per year, assuming no seasonal variation. $116(85 \%)$ of the cases were referred for CAMHS assessment, 105 (90\%) received this during their inpatient stay and 86 had been seen by the following day. 26 (21\%) of the patients were recorded as having their discharge delayed by CAMHS factors by more than 1 day and $14(10 \%)$ had a delay of 4 or more days. Difficult or dangerous events occurred during $26(17 \%)$ of the admissions. $32(24 \%)$ admissions involved current CAMHS patients. $119(87 \%)$ of the admissions followed acts of deliberate self harm or substance abuse.

Conclusions: The impact of CAMHS need on acute paediatric units has been assessed, with implications for service provision. The discharge of these patients is often delayed while waiting for CAMHS assessment or treatment.

\section{G187 AN EVALUATION OF THE EFFICACY OF USING TEA-CH TO ASSIST THE ASSESSMENT AND DIAGNOSIS OF ADHD IN CHILDREN}

A. Hughes, L. Martel. Warren Children's Centre, Down Lisburn Trust, Northern Ireland, UK

Aims: A research study was carried out to evaluate the usefulness of the Test of Everyday Attention for Children (Manly et al, 1998) in identifying attention deficits and evaluating the nature of attentional dysfunction in children with ADHD. TEA-Ch is a neuropsychological assessment tool designed to measure a range of attentional abilities in children aged between 6-16 years of age.

Method: A sample of 35 children with ADHD aged between 6-12 years of age was compared with the results of a normative control sample matched for age and sex. Analysis of Variance (ANOVA) was carried out to compare performance of the clinical and normative sample on TEA-Ch subtests.

Results: The results indicate that children with ADHD perform at a comparable level to matched peers on measures of visual selective attention, however their performance on measures of auditory divided attention and sustained attention was significantly poorer than the control sample. Children with ADHD also demonstrated significant difficulty on tests which measure the ability to switch attention and behavioural inhibition compared to the control sample.

Conclusions: The results of this study indicate that TEA-Ch is a useful clinical tool that can identify an attentional profile of ADHD and help distinguish children with ADHD from those of a normative control sample. This information can inform clinical and educational professionals on the nature of attentional functioning of children with ADHD.

\section{G188 ARE WE NICE ENOUGH-AUDIT OF INITIAL ASSESSMENT AND MANAGEMENT OF ATTENTION DEFICIT/HYPERACTIVITY DISORDER (ADHD) IN A SEMI URBAN DISTRICT}

Z. Bassi, M.L. Yeap, I.L. Omenaka. Warrington Community NHS Trust, UK

Introduction: Recent literature has highlighted the importance of audit in the management of children with ADHD'

Aims: To audit the initial assessment and management and subsequent follow up of all newly diagnosed children with ADHD in our district using the guidance published by the National Institute for Clinical Excellence and clinical practice guidelines of the American Academy of Paediatrics

Methods: A retrospective case note study was performed on all children diagnosed with ADHD between 1/00 to 12/00.

Results: Forty children were identified from the community child healthcare database of which $38(98 \%)$ were male. Four patients were $<6,25$ were between 6 to 10, and the rest $>10$ years. Eighty percent of patients were under the care of community paediatrician and rest under psychiatrist. School assessment reports were present in 38 notes. Twenty-four children had associated co morbidities. Management strategies included dietary $(n=4)$, behavioural $(n=31)$, medication $(n=33)$ and others $(n=12)$. Eighty percent had documented 
feedback to parents and school. Of the patients on medication $88 \%$ were on methylphenidate. These patients had weekly telephone feedback for dose adjustment and subsequent outpatient follow up for monitoring. Only $25 \%$ had documented recommended monitoring on initiation and at six months. Ten patients $(30 \%)$ experienced side effects and drug had to be discontinued in $3(9 \%)$ patients.

Conclusions: Our service met most of the good practice guidelines but some deficiencies were identified in the monitoring of children on methylphenidate. An integrated care pathway has been developed for improved monitoring and joint care pathways with general practitioners are being devised for their input.

1. Hill P, Taylor E. An auditable protocol for treating ADHD. Arch Dis Child 2001;84:404-9. 